\title{
Relationship Between Burnout and Quality of Care in Nurses in Banten, Indonesia: A Cross-Sectional Study
}

\section{Eli Amaliyah 1,2,* and Tukimin Sansuwito ${ }^{2}$}

${ }^{1}$ Faculty of Nursing, Lincoln University College, Malaysia

${ }^{2}$ Department of Nursing, Faculty of Medicine, Universitas Sultan Ageng Tirtayasa, Indonesia

\section{ORCID}

Eli Amaliyah:https://orcid.org/0000-0003-0057-8825

Corresponding Author: Eli Amaliyah; email:

eli.amaliyah@untirta.ac.id

Published: 7 February 2022

Publishing services provided by Knowledge E

(c) Eli Amaliyah and Tukimin Sansuwito. This article is distributed under the terms of the Creative Commons

Attribution License, which permits unrestricted use and redistribution provided that the original author and source are credited.

Selection and Peer-review under the responsibility of the IVCN Conference Committee.
Abstract. Nurses are legally liable and morally responsible for the quality of the care they provide to patients. Nursing is considered to be a high-risk working group, that is high pressure and involves constantly having to handle the needs and emergency conditions of patients. This puts them in conditions with a higher risk of burnout. This cross-sectional study was carried out with nurses at general public hospitals in Banten, Indonesia. Data were collected from January to March 2021. All participants were staff nurses in either the medical, surgical, obstetric, or pediatric care units working in direct care. The total sample was 180. Convenience sampling was used. Burnout was measured using the Maslach Burnout Inventory Human Service Survey. The patient's perception of nursing care quality was measured using a modified instrument. Linear regression analyses were used to investigate the factors associated with quality of care. Most of the nurses (58.33\%) had a nursing diploma, and $7 \%$ had been married. Approximately 70\% were nurses at the level 1 to 3 range. The mean score was 3.56 $(S D=1.33)$. The highest domains score was comfort $(4.24, S D=1.44)$, and the lowest score was physical environment $(2.89, \mathrm{SD}=0.81)$. Burnout and quality of care showed a significant correlation with $r$ ranging from 0.37 to 0.65 , with $p<0.05$. Nurses are the largest segment of healthcare professionals and so measuring the quality of nursing care is critical for improving practice. Interventions to improve nursing care quality by considering nurse burnout are needed.

Keywords: burnout, quality of care, nurse, Indonesia

\section{Introduction}

Nurses are legally liable and morally responsible for the quality of the care they provide to patients [1] They are aware of its responsibility for the quality of its care provision to the patients, the institution, ethics, laws and professional standards, and how its performance contributes to the assessment of care and patient satisfaction. Patient can experience negative healthcare when nursing care is sub-optimal [2]. Previous studies have found that a lack of high-quality nursing care increases the risk of negative

\section{G OPEN ACCESS}


incidents, readmission, failure to rescue and mortality rates [3-5]. In addition, study suggested that improving the quality of care is important worldwide, which cost about $\$ 1.3$ trillion and takes care of about 1.5 million over 65-year-olds each year [6].

The international study was carried out in South Korea, Japan, China and Germany identified that the standard of nursing care was as good or as poor as $68 \%, 60 \%, 30 \%$ and $20 \%$ respectively [7]. Studies in Tanzania reported that more than half described staff interactions that were disrespectful, not polite, or not helpful only $51 \%$ of patients had time to ask questions [8]. Moreover, in in-depth interviews and birth narratives, $46 \%$ of patients highlighted harassing or disrespectful care and $38 \%$ reported ignoring or dismissing their queries. Similarly, in other settings, negative nursing quality reporting seems to be mainly based on qualitative methods [9]. Moreover, a study of user satisfaction predictors in nursing showed that very higher customer satisfaction ratings can represent an incomprehension of exposure, particularly in low-income patients [10].

Nursing is considered to be a high-risk working group, high pressure and constantly having to handle the needs and emergency conditions of patients, perhaps putting them in a condition with a higher risk of burnout profession [11]. Among young nurses, study reported that short-staffing and work-life interference are important factors influencing burnout. Developing nurse managers' authentic leadership behaviours and working with them to create and sustain empowering work environments may help reduce burnout, increase nurse job satisfaction and improve patient care quality [12]. A study in Oman reported that a foundation for quality of care, and staffing adequacy were predictors of burnout among nurses and perceived quality of care [13]. Therefore, this study aimed to explore relationship between burnout and quality of care among nurses in Banten, Indonesia.

\section{Methods}

\subsection{Study design}

A cross-sectional study was carried out the Nurses at general public hospitals in Banten, Indonesia. Data was collected from January to March 2021.

\subsection{Sample}

The target population of this study was a nurse and patients at two general public hospital located in Serang Banten, Indonesia. Banten general public hospital with 500 
to 6000 beds respectively. In total there were about 518 nurses working at two general public hospital in Serang, Banten Indonesia. All participants were staff nurses in either the medical, surgical, obstetric, and pediatric care units working in direct care. One of the investigators invited participants to volunteer to take part in the study. Respondents could electronically complete the self-report questionnaires either at home and/or in the hospital.

The sample size was calculated using G-Power Software version 3.1.6 using the $F$ test assumed to be $\alpha=0.05$, effect size $=0.15$ (Cohen et al 1995 medium effect size), power level $=0.95$. It was result in an estimate of 150 for the minimum sample and assuming an attrition rate of 15 percent, so the total minimum sample is 180 . Convenience sampling technique was used. Participants was recruited from medical surgical, obstetric, and pediatric care units.

\subsection{Instrument}

The patient's perception of nursing quality care which is a modified instrument originally developed by Senarath et al. (2011). This instrument measure quality of care according to interpersonal aspects (.68-.85), efficiency (.62-.79), competency (.66-.68), comfort (.60-.84), physical environment (.65-.82), cleanliness (.81-.85), personalized information (.76-.83), and general instructions (.61-.78). The 5-point Likert scale ranged from fully agree (5) to fully satisfied (1), with an alternative one "do not know" (0). A high score meant high quality nursing care and was divided into three levels. The instrument had high Internal consistency (Cronbach's alpha = .91). (Senarath, 2011).

Burnout was measured using the Maslach Burnout Inventory Human Service Survey (MBI) [14], a 22-part survey of tested subscales [15,16] using 20 items covering three separate dimensions: emotional exhaustion (8 items), depersonalization (5 items) and personal execution (7 items). Respondents rated the frequencies with which they experience different job-related feelings on a scale of seven points, ranging from never to every day. High scores on emotional exhaustion and depersonalization, and low scores on the scale of personal accomplishment are considered burnout indicative.

\subsection{Procedure}

Nurses completed self-report surveys after providing written, informed consent. In the study period from January to March 2021, the total 518 nurses as well as 180 participants who participated in an online questionnaire. It was only after the researcher had 
TABLE 1: Demographic and clinical characteristics and the score of quality of care among nurses $(n=180)$

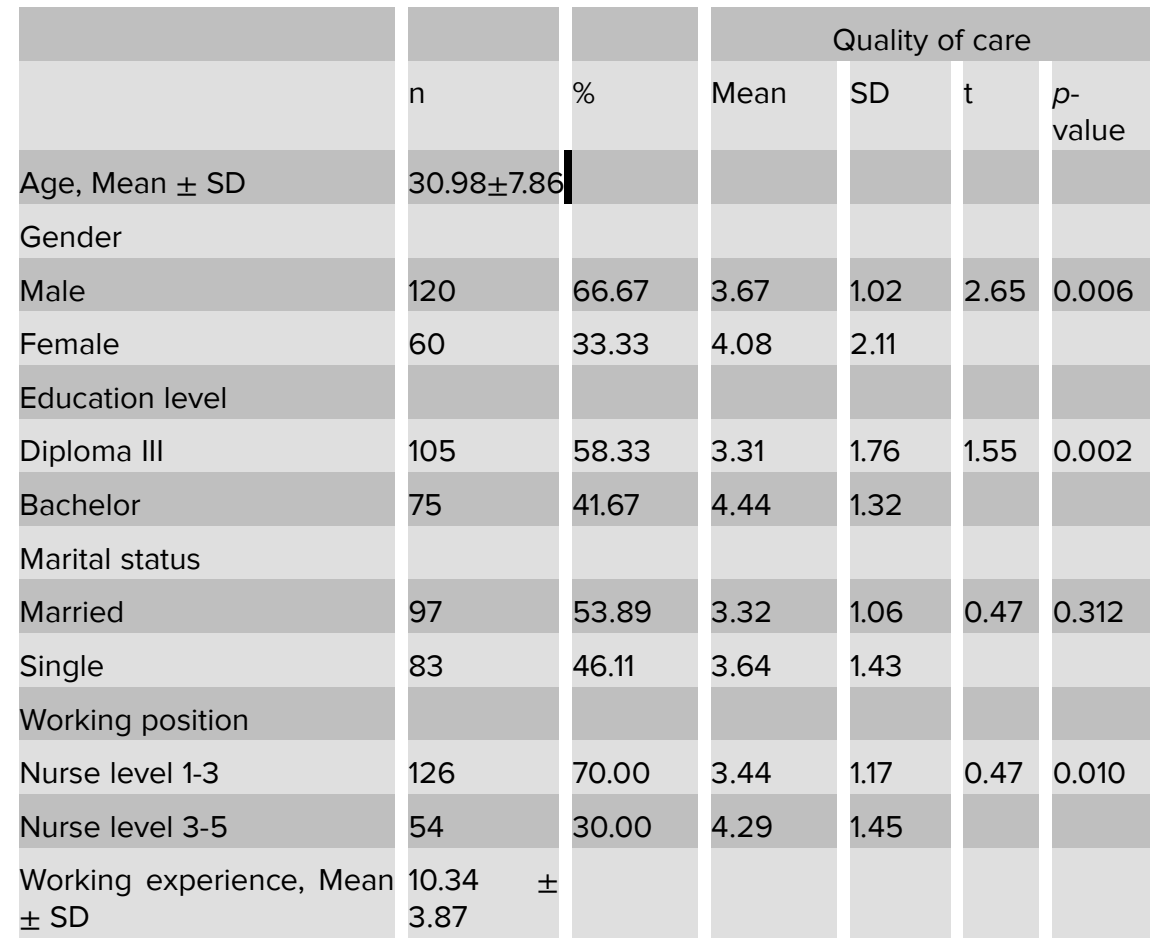

fully discussed the aims of the investigation and gained managerial consent that he published information about the study. If any participants had questions as they went through the survey, the researcher was there to help them immediately.

\subsection{Data analysis}

This study was employed by the independent $t$ test to describe different demographic of quality of care. Linear regression analyses were used to investigate the factors associated with quality of care. The statistical analyses were performed using SPSS for Windows (22.0), with 0.05 being considered statistically significant.

\section{Results}

Most of them (58.33\%) had a nursing diploma, and $7 \%$ had been married. Approximately $70 \%$ were nurses at the level 1 to 3 range. Participants had an average of 18.87 years of nursing experience (SD = 6.34). Gender, education level, and working position was significantly different in terms of quality of care (Table 1).

Table 2 shows descriptive analysis of quality of care. The mean score was 3.56 $(S D=1.33)$. The highest domains score was comfort $(4.24, S D=1.44)$, with the lowest 
TABLE 2: A descriptive statistic of quality of care $(n=120)$

\begin{tabular}{l|l|l|l} 
& Mean \pm SD & Burnout $r$ & p-value \\
\hline Overall score & $3.56 \pm 1.33$ & 0.45 & 0.001 \\
\hline Interpersonal efficiency & $3.02 \pm 1.51$ & 0.65 & 0.001 \\
Competency & $3.65 \pm 1.87$ & 0.38 & 0.001 \\
\hline Comfort & $4.24 \pm 1.44$ & 0.54 & 0.001 \\
\hline Physical environment & $2.78 \pm 1.57$ & 0.38 & 0.001 \\
\hline Cleanliness & $2.89 \pm 0.81$ & 0.44 & 0.001 \\
\hline Personalized information & $3.54 \pm 1.03$ & 0.52 & 0.001 \\
\hline General instructions & $2.88 \pm 1.56$ & 0.37 & 0.001
\end{tabular}

TABLE 3: Simple linear regression analysis results of quality of care among nurses $(n=120)$

\begin{tabular}{l|l|l} 
Variable & Overall score $B(\mathrm{SE})$ & $p$-value \\
\hline Gender & $0.113(0.044)$ & 0.001 \\
\hline Education level & $0.245(0.056)$ & 0.001 \\
\hline Working position & $0.299(0.076)$ & 0.001 \\
\hline Burnout & $-0.308(2.09)$ & 0.001 \\
$\mathrm{R}^{2}$ & 0.327 &
\end{tabular}

score was physical environment $(2.89, \mathrm{SD}=0.81)$. Burnout and quality of care showed a significant correlation with $r$ ranged from 0.37 to 0.65 , with $p<0.05$.

Table 3 shows simple linear regression analysis results of quality of care. Gender, education level, working positions, and burnout was associated contributed significantly to the variance in quality of care with $\mathrm{R}$ square was $32.7 \%$ (Table 3 ).

\section{Discussion}

This study found that nurse has higher level of burnout. Recent study conducted in the US reported that higher prevalence of personal burnout was $52.7 \%(95 \% \mathrm{Cl} 50 \%$ to $55 \%)$, work-related burnout $47.5 \%(95 \% \mathrm{Cl} 45 \%$ to $49 \%)$ and patient/client-related burnout $20.3 \%(95 \% \mathrm{Cl} 18 \%$ to $22 \%$ ) among clinicians and scientists [17]. Previous study found that the nurse burnout occurs not only with the freshly graduated nurses but also with the senior nurses, including the head nurses [18]. Research [19] about burnout in nurses in Taiwan, the results of his study obtained $54.0 \%$ of 1,846 nurses in Taiwan experienced burnout syndrome. Similar research was also carried out in Brazil which states that around $55.3 \%$ of 130 nurses experienced burnout, especially in the Intensive Care Unit [20]. In Indonesia, previous study reported that many of nurses (42.9\%), especially in intensive care unit experienced emotional exhaustion and depersonalization [21]. 
Another study conducted in Jakarta found that the level of nurse burnout was higher and there was a significant relationship between burnout and nurse performance [22].

Findings of this study found that burnout significantly associated with quality of care. Prior studies have also examined the relationship between nurse burnout and quality of care. Findings indicated that across countries, higher levels of burnout were associated with poor quality of care $[23,24]$. [25] suggested that positive work environments were associated with lower nurse job dissatisfaction, less burnout, higher quality of care, and safer care. Burnout largely and directly influenced quality nursing care, which was followed by work environment and patient-to-nurse ratio. Job satisfaction indirectly affected quality nursing care through burnout [26]). Among young nurses, study reported that short-staffing and work-life interference are important factors influencing burnout. Developing nurse managers' authentic leadership behaviours and working with them to create and sustain empowering work environments may help reduce burnout, increase nurse job satisfaction and improve patient care quality [12]. A study in Oman reported that a foundation for quality of care, and staffing adequacy were predictors of burnout among nurses and perceived quality of care [13].

\section{Conclusion}

This study found that nurse's quality of care was moderate. Gender, education level, and working position was significantly different in terms of quality of care. Burnout was significantly associated with nursing quality of care. Nurses are the largest segment of healthcare professionals and so measuring the quality of nursing care is critical to improving practice. Poor nursing quality can significantly increase negative outcomes for patients, such as infection with the urinary tract, falling patients, pressure ulcers, critical incident and readmission. Intervention to improve nurse quality of care by considering nurse burnout is needed.

\section{Conflict of interest}

None.

\section{Funding}

No Funding for this research. 


\section{References}

[1] Snowdon DA, Leggat SG, Taylor NF. Does clinical supervision of healthcare professionals improve effectiveness of care and patient experience? A systematic review. BMC Health Serv Res. 2017;17(1):1-11.

[2] Van der Heijden B, Brown Mahoney C, Xu Y. Impact of Job Demands and Resources on Nurses' Burnout and Occupational Turnover Intention Towards an Age-Moderated Mediation Model for the Nursing Profession. Int J Environ Res Public Health. 2019 Jun;16(11).

[3] Aiken LH, Sloane DM, Bruyneel L, Van den Heede K, Griffiths P, Busse R, et al. Nurse staffing and education and hospital mortality in nine European countries: a retrospective observational study. Lancet (London, England). 2014 May;383(9931):1824-30.

[4] Ball JE, Murrells T, Rafferty AM, Morrow E, Griffiths P. "Care left undone" during nursing shifts: associations with workload and perceived quality of care. BMJ Qual Saf. 2014 Feb;23(2):116-25.

[5] McHugh MD, Stimpfel AW. Nurse reported quality of care: a measure of hospital quality. Res Nurs Health. 2012/08/21. 2012 Dec;35(6):566-75.

[6] Care Quality Commission. The state of health care and and adult social care in England 2013/2014. London; 2014.

[7] Aiken LH, Cimiotti JP, Sloane DM, Smith HL, Flynn L, Neff DF. Effects of nurse staffing and nurse education on patient deaths in hospitals with different nurse work environments. Med Care. 2011 Dec;49(12):1047-53.

[8] Tancred T, Schellenberg J, Marchant T. Using mixed methods to evaluate perceived quality of care in southern Tanzania. Int J Qual Heal care. 2016;28(2):233-9.

[9] van den Driessen Mareeuw FA, Coppus AMW, Delnoij DMJ, de Vries E. Quality of health care according to people with Down syndrome, their parents and support staff-A qualitative exploration. J Appl Res Intellect Disabil. 2020;33(3):496-514.

[10] Triyanto J, Janjua PZ, Samad G, Khan N, Ishaq M, Rumiati AT, et al. No Title. J Sains dan Seni ITS [Internet]. 2017;6(1):51-66. Available from: http://repositorio. unan.edu.ni/2986/1/5624.pdf\%OA http://fiskal.kemenkeu.go.id/ejournal\%OA http:// dx.doi.org/10.1016/j.cirp.2016.06.001\%0A http://dx.doi.org/10.1016/j.powtec.2016.12. 055\%0A https://doi.org/10.1016/j.jjfatigue.2019.02.006\%0A

[11] Gracia-Gracia P, Oliván-Blázquez B. Burnout and mindfulness self-compassion in nurses of intensive care units: cross-sectional study. Holist Nurs Pract. 2017;31(4):225-33. 
[12] Boamah SA, Read EA, Spence Laschinger HK. Factors influencing new graduate nurse burnout development, job satisfaction and patient care quality: a time-lagged study. J Adv Nurs. 2017;73(5):1182-95.

[13] Al Sabei SD, Labrague LJ, Miner Ross A, Karkada S, Albashayreh A, Al Masroori F, et al. Nursing work environment, turnover intention, job burnout, and quality of care: the moderating role of job satisfaction. J Nurs Scholarsh. 2020;52(1):95-104.

[14] Maslach C, Jackson SE, Leiter MP, Schaufeli WB, Schwab RL. Maslach Burnout Inventory 3rd edition manual. Mt View, CA CPP Inc. 1996;

[15] Maslach C, Schaufeli WB, Leiter MP. Job burnout. Annu Rev Psychol. 2001;52:397422.

[16] Van Bogaert P, Clarke S, Roelant E, Meulemans H, Van de Heyning P. Impacts of unit-level nurse practice environment and burnout on nurse-reported outcomes: a multilevel modelling approach. J Clin Nurs. 2010 Jun;19(11-12):1664-74.

[17] Messias E, Gathright MM, Freeman ES, Flynn V, Atkinson T, Thrush CR, et al. Differences in burnout prevalence between clinical professionals and biomedical scientists in an academic medical centre: a cross-sectional survey. BMJ Open. 2019;9(2):e023506.

[18] Luan X, Wang P, Hou W, Chen L, Lou F. Job stress and burnout: A comparative study of senior and head nurses in China. Nurs Health Sci. 2017 Jun;19(2):163-9.

[19] Lee H-F, Yen M, Fetzer S, Chien T. Predictors of Burnout Among Nurses in Taiwan. Community Ment Health J. 2014 Dec;51.

[20] da Silva JLL, Soares R da S, Costa F dos S, Ramos D de S, Lima FB, Teixeira LR. Psychosocial factors and prevalence of burnout syndrome among nursing workers in intensive care units. Rev Bras Ter intensiva. 2015;27(2):125-33.

[21] Halizasia G, Putra A. KEJENUHAN KERJA PADA PERAWAT DIRUANG INTENSIVE CARE RUMAH SAKIT UMUM DAERAH dr. ZAINOEL ABIDIN BANDA. J IIm Mhs Fak Keperawatan. 2017;2(3).

[22] Suharti N, Daulima N. Burnout dengan Kinerja Perawat di Rumah Sakit Metropolitan Medical Centre Jakarta. Univ Indones. 2013;

[23] Van Bogaert P, Adriaenssens J, Dilles T, Martens D, Van Rompaey B, Timmermans O. Impact of role-, job-and organizational characteristics on Nursing Unit Managers' work related stress and well-being. J Adv Nurs. 2014;70(11):2622-33.

[24] Van Bogaert P, Kowalski C, Weeks SM, Van Heusden D, Clarke SP. The relationship between nurse practice environment, nurse work characteristics, burnout and job outcome and quality of nursing care: a cross-sectional survey. Int J Nurs Stud. 2013 Dec;50(12):1667-77. 
[25] Liu J, Zhu B, Wu J, Mao Y. Job satisfaction, work stress, and turnover intentions among rural health workers: a cross-sectional study in 11 western provinces of China. BMC Fam Pract. 2019 Jan 14;20.

[26] Liu Y, Aungsuroch Y. Factors influencing nurse-assessed quality nursing care: $A$ cross-sectional study in hospitals. J Adv Nurs. 2018;74(4):935-45. 